\section{Atypical Fibroadenoma Presentation of a Case}

\author{
Juana Teresa Santiago Pérez ${ }^{1 *}$, José Miguel González Barcena², \\ Yuranis Gárciga Martin ${ }^{3}$ and Yahumara Suarez Morales ${ }^{3}$ \\ 12nd grade specialist and Professor of General Surgery, University of Medical Sciences of Havana, \\ Cuba \\ ${ }^{2} 1$ st grade specialist and Assistant Professor of General Surgery, University of Medical Sciences of \\ Havana, Cuba \\ ${ }^{3} 1$ st degree specialist in General Surgery, Cuba
}

Received: 23 December, 2019

Accepted: 09 November, 2020

Published: 10 November, 2020

*Corresponding author: Juana Teresa Santiago Pérez, 2nd grade specialist and Professor of General Surgery, University of Medical Sciences of Havana, Freyre de Andrade No. 114 / D`Strampes and Juan Delgado Sevillano, Havana, Cuba, Tel: +53 52967490; E-mail: teresasp@infomed.sld.cu

Keywords: Giant fibroadenoma; Breast; Fillodes tumor https://www.peertechz.com

Check for updates

\title{
Summary
}

Fibroadenoma is the most frequent benign tumor of the breast, although its classification as a true benign tumor or as a mastopathy related to circulating estrogens is discussed today.

They usually occur below 30 years and constitute $76 \%$ of breast masses between 10 and 20 years. Bilateralism has been reported between 12 and $16 \%$ of fibroadenomas. The type called Juvenile or Giant only reaches $2 \%$ of all Fibroadenomas and $7 \%$ of all lesions of the breast in children under 20 years.

The most common form of presentation is like a solid, mobile and painless tumor that can acquire a large size.

The diagnosis of these masses is made with physical examination and imaging techniques, mainly ultrasound.

The diagnostic confirmation is given by the histological study.

The surgical treatment must be individualized in each case, taking into account its particularities.

We present the case of a 72-year-old woman who goes to an outpatient clinic for a giant tumor in the breast, imaging and histological studies are possible, and by joint decision in the multidisciplinary team the surgical treatment is decided and surprisingly the histological result, results in a giant fibroadenoma of the breast.

\section{Introduction}

Fibroadenoma is the most common benign breast lesion in women below 30 years. They are usually lesions associated with early ages of life [1] Its most common form of presentation is a hard, painless and mobile mass that can have a large size. The diagnosis is made regularly with imaging tests, with ultrasound being the method of choice in young patients, although mammography and nuclear magnetic resonance imaging are diagnostic tools, in women over 35 years. From the histological point of view it is a mixed tumor in which there is proliferation of the intralobular stromal connective tissue, and a cluster multiplication of the ducts $[2,3]$.

\section{Objective}

Show a 72-year-old patient with a giant fibroadenoma, whose clinical presentation was unusual.

\section{Method}

The corresponding complementary studies were performed: Imaging (ultrasound) mammography is not performed due to local breast conditions; BAAF is performed that is hemorrhagic, so the surgical intervention is decided, after discussion in the multidisciplinary team.

\section{Presentation of the case}

Patient AMP, a 72-year-old female, with a history of hypertension, who has been systematically treated with Captopril and remains under control, reports that since February 2018, she has observed a non-painful increase in the volume of the right breast, with redness of the area and which has grown markedly only in three months. In the rest of the interrogation, there are no data that point to the risk factors for breast cancer. 
The physical examination shows skin with an increase in the important vascularization, which occupies the central region of the right breast, in a radiated way towards the four quadrants, a tumor mass of firm consistency (not stony) is not felt painfully defined but not defined edges irregular.

The axillary region is examined and ipsilateral lymph nodes, not supraclavicular nodes, are confirmed Figure 1a,b.

Imaging studies (ultrasound) are performed; Mammography is not performed due to the characteristics of the physical examination of the breast, considering that it was not suitable for the compression of the organ required by this study.

Figure 2 shows the particularities found:

It also proceeds to perform fine needle aspiration biopsy, which does not provide guiding results, as the blades showed extended hemorrhagic, not useful for diagnosis Figure 3.

After discussing the case thoroughly by the multidisciplinary team, it is decided to perform the exeresis of the lesion and confirmation by transoperative biopsy.

This biopsy is negative for neoplastic cells and suggests waiting for paraffin cuts Figure 4a,b.

\section{Pathological anatomy}

The results of the paraffin study show the characteristics of a giant fibroadenoma, which in the macroscopic description measured $10 \times 13$ centimeters. In the histological sections the cellularity of the stroma was demonstrated, as well as the epithelial component Figure 5.

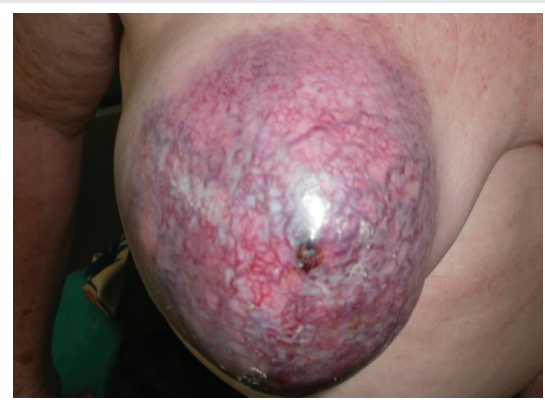

Figure 1a: Presence of tumor mass that occupies the central region of the right breast, of firm consistency, not painful, very vascularized (Front view).

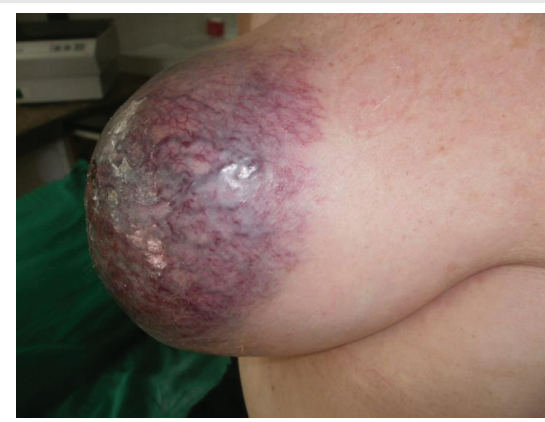

Figure 1b: The same characteristics (Side view)

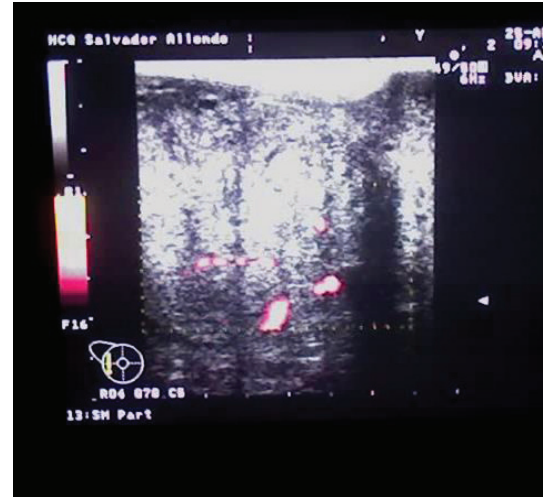

Figure 2:

They have sharp edges, they can be lobed.

$\checkmark \quad$ They are hyperechoic or hypoechoic with a homogeneous structure.

$\checkmark$ They do not alter the structure of neighboring tissues.

$\checkmark$ The largest diameter is transverse.

Have shadows.

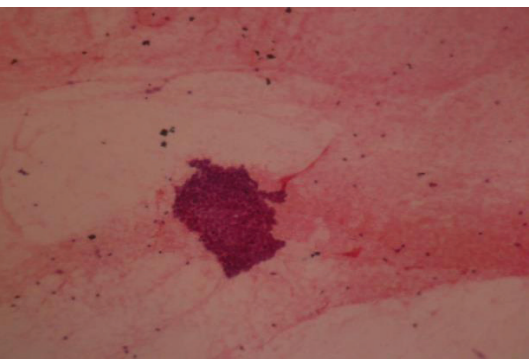

Figure 3: Cytological study (BAAF C96-2018), Resulting in: Extended hemorrhagic

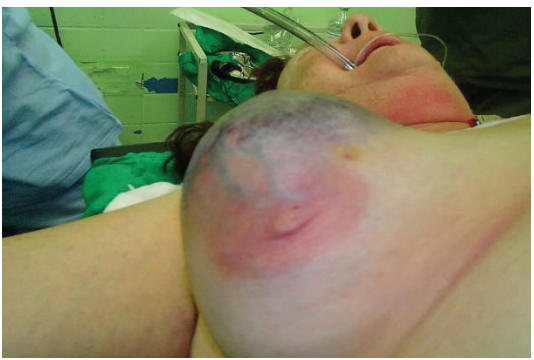

Figure 4a: Patient in the Operating Room Ready for exeresis of the injury.

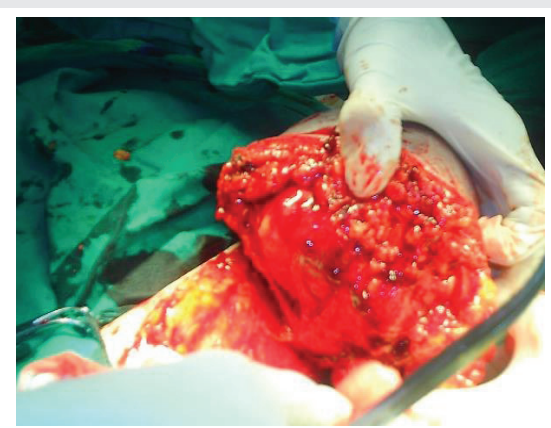

Figure $\mathbf{4 b}$ : Moment of the Lumpectomy.

\section{Discussion}

Fibroadenoma is a very common benign breast lesion. They are composed of glandular and stromal tissue (connective). Within benign lesions, in terms of frequency, they are only 


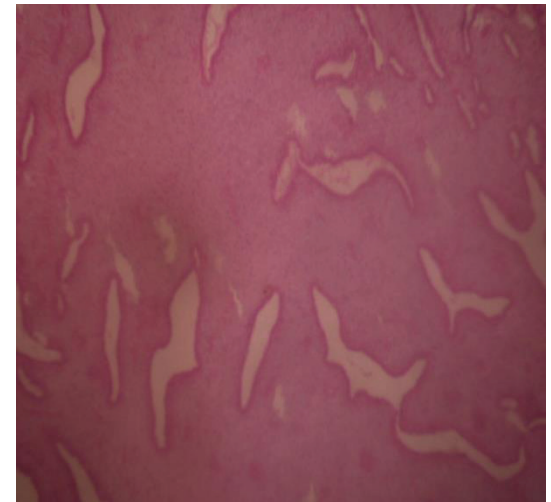

Figure 5: Histological section at higher magnification highlighting not only the epithelial component of the tumor, but also the increase in stromal cellularity.

preceded by the Fibrocystic Breast Condition (breast dysplasia) as it is also known [3-5].

Many times they appear during puberty, and in younger girls but they are more frequent in women of little more than twenty years. Other authors report their age of onset, between the ages of 20 and 35 years of age [5]. However, this type of injury is unlikely to appear in postmenopausal women $[5,6]$.

Usually, the reason for consultation is the appearance of a lump in one of the breasts, not painful and fast growing. On physical examination, when they are palpable they can be well defined, they are movable, sometimes giving an elusive sensation, during the exploration. The size ranges from a few millimeters to several centimeters (most are 1 to $3 \mathrm{~cm}$ ). In those very small lesions, the diagnosis is a fortuitous finding [6-9].

Mammography and ultrasound represent the two fundamental diagnostic pillars in terms of imaging tests. The definitive diagnosis is the histological study, which in large tumors is essential for the diagnosis of benignity, in addition, the histological study will allow the differential diagnosis to be completed with other entities: lipomas, hamartomas, fatty necrosis, giant abscesses, papillomas, etc [7-10].

The treatment should be individualized and whenever possible, especially in large tumors, the removal or excision of the tumor will be performed for the complete pathological study of the piece. In cases of giant tumors, a mastectomy may be necessary. Some authors in these cases advocate a mastectomy with posterior breast reconstruction $[9,11,12]$.

When it becomes necessary to assume aggressive surgical treatment, it is important to take into account the aesthetic result as well as protect the breast, areola and nipple unit since in girls and adolescent patients, it is still in full development $[3,8,9]$.

In the case at hand, we had to resort to mastectomy, as evidently the lesion invaded the entire breast and on the other hand, the result of the paraffin biopsy was really a surprise when reporting a benign lesion, taking into account the age of the patient and the preoperative studies that did not provide the necessary results due to the condition of the skin or the vascularization of the lesion.

This case was against all expected expectations, due to the age of the patient and the peculiarities of tumor presentation.

\section{Conclusion}

An unusual form of presentation of the Giant Fibroadenoma is presented, since this disease is usually shown in early ages of female life and it is not usual to appear in older people as it happened in this patient. In addition, it is not frequent to take the skin as it happened in this case, which led the multidisciplinary team to the surgical decision as the first treatment weapon despite the dimensions of the tumor, since the diagnostic means could not offer convincing results.

\section{References}

1. Sklair-Levy M, Sella T, Alweiss T, Craciun I, Libson E, et al. (2008) Incidence and management of complex fibroadenomas. AJR Am J Roentgenol 190: 214-218. Link: https://bit.ly/3eE0AQ1

2. Smith GEC, Burrows $P$ (2008) Ultrasound diagnosis of fibroadenoma - is biopsy always necessary?. Clin Radiol 63: 511-515. Link: https://bit.ly/3p6NLCJ

3. Michalina K, Brian Y, Suela S, Heidi M (2017) Giant juvenile fibroadenoma in a 9-year-old: A case presentation and review of the current literature. Breast Dis 37: 95-98. Link: https://bit.ly/3lcSReb

4. Gao Y, Saksena MA, Brachtel EFI, terMeulen DC, Rafferty EA (2015) How to approach breast lesions in children and adolescents. Eur J Radiol 84: 13501364. Link: https://bit.ly/3keDoZL

5. Sosin M, Pulcrano M, Feldman ED, Patel KM, Nahabedian MY, et al. (2015) Giant juvenile fibroadenoma: A systematic review with diagnostic and treatment recommendations. Gland Surgery 4: 312-321. Link: https://bit.ly/2lansuN

6. Rafeek N, Rangasami R, Dhanraj K, Joseph S (2016) Multimodality approach in the diagnosis and management of bilateral giant juvenile breast fibroadenoma. BMJ Case Rep 2016. Link: https://bit.ly/3eHxC1F

7. Duflos C, Plu-Bureau G, Thibaud E, Kuttenn F (2012) Breast diseases in adolescents. Pediatric and adolescent gynecology. Evidence-based clinical practice $2^{\text {nd }}$ ed. 22: 208-221. Link: https://bit.ly/3n7KelK

8. Van Osdol $A D$, Landercasper J, Andersen $\mathrm{JJ}$, Ellis RL, Gensch EM, et al. (2014) Determining whether excision of all fibroepithelial lesions of the breast is needed to exclude phyllodes tumor: Upgrade rate of fibroepithelial lesions of the breast to phyllodes tumor. JAMA Surg 149: 1081-1085. Link: https://bit.ly/35cc8qE

9. Matz D, Kerivan L, Reintgen M, Akman K, Lozicki A, et al. (2013) Breast preservation in women with giant juvenile fibroadenoma. Clin Breast Cancer 13: 219-222. Link: https://bit.ly/3kjwG4U

10. Ross DS, Giri DD, Akram MM, Catalano JP, Olcese C, et al. (2017) Fibroepithelia lesions in the breast of adolescent females: A clinicopathological study of 54 cases. Breast J 23: 182-192. Link: https://bit.ly/3pdVcrs

11. Cabrera G, Monduy R, Frías O, Cabrera CA (2017) Tumor phyllodes de la mama Rev Ciencias Médicas Pinar del Río 15: 11. Link: https://bit.ly/21960M1

12. Torres L (2012) Tumor phyllodes de la mama: estudio de 32 años. Finlay 2: 8 . Link: https://bit.ly/3pbxOLq

Copyright: (c) 2020 Santiago Pérez JT, et al. This is an open-access article distributed under the terms of the Creative Commons Attribution License, which permits unrestricted use, distribution, and reproduction in any medium, provided the original author and source are credited. 